\title{
How to interpret symptoms, signs and investigations of dehydration in children with gastroenteritis
}

\author{
Antonio Prisco, Daniela Capalbo (D) , Stefano Guarino, \\ Emanuele Miraglia del Giudice, Pierluigi Marzuillo
}

Department of Woman, Child and of General and Specialized Surgery, Università degli Studi della Campania Luigi Vanvitelli, Napoli, Italy

\section{Correspondence to}

Dr Pierluigi Marzuillo, Department of Woman, Child and of General and Specialized Surgery, Università degli Studi della Campania Luigi Vanvitelli, Naples 80138, Italy; pierluigi. marzuillo@gmail.com

Accepted 10 June 2020 Published Online First 24 July 2020

\section{Check for updates}

(c) Author(s) (or their employer(s)) 2021. No commercial re-use. See rights and permissions. Published by BMJ.

To cite: Prisco A, Capalbo D, Guarino $S$, et al. Arch Dis Child Educ Pract Ed 2021;106:114-119.

\begin{abstract}
Dehydration is a significant cause of morbidity and mortality in children worldwide. Infants and young children are vulnerable to dehydration, and clinical assessment plays a pivotal role in their care. In addition, laboratory investigations can, in some children, be helpful when assessing the severity of dehydration and for guiding rehydration treatment. In this interpretation, we review the current literature and provide an evidence-based approach to recognising and managing dehydration in children.
\end{abstract}

\section{BACKGROUND}

Worldwide, it has been estimated that approximately one in five paediatric deaths can be attributed to dehydration related to gastroenteritis. ${ }^{12}$ The increased fluid losses from vomiting and diarrhoea can result in rapid fluid and electrolyte shifts leading to dysregulation of physiological mechanisms such as thirst. In extremis, this can lead to volume depletion and dangerous electrolyte imbalances. ${ }^{1}$ An understanding of the symptoms, signs and investigations used to assess and manage dehydration is vital for any clinician caring for acutely unwell children. This interpretation therefore focuses entirely on the management of dehydration in children with an acute gastrointestinal illness. Other, less common, causes of dehydration (eg, diabetic ketoacidosis, renal failure, cardiac failure, liver disease and postoperative care) are not covered.

Throughout this interpretation, dehydration will be described as mild $(<5 \%$ of weight loss), moderate (5\%-10\% weight loss) or severe (>10\% weight loss). ${ }^{3}$

\section{WHAT ARE THE SYMPTOMS AND SIGNS OF DEHYDRATION IN A CHILD?}

A number of clinical features were identified from the literature as predictive of dehydration. These are outlined in table 1 and include decreased skin turgor, capillary refill time of $>2 \mathrm{~s}$, ill appearance, absent tears, abnormal respiration pattern, dry mucous membranes, sunken eyes, abnormal (weak or feeble) radial pulse, tachycardia and decreased urine output. ${ }^{4-7}$ The absence of these signs, among children with gastroenteritis, was highly predictive of the child not having dehydration with a negative predictive value (NPV) of over $90 \%{ }^{4-7}$

Unfortunately, the symptoms and signs listed above and in table 1 were not specific for dehydration; that is, the presence of one or more of the symptoms could not be used to accurately confirm dehydration as present. The most specific symptoms and signs of dehydration were reported as prolonged capillary refill time of $>2 \mathrm{~s}$ (positive predictive value (PPV) $0.57-$ 0.65 ) and decreased skin turgor (PPV $0.52-0.57)$. The remaining symptoms and signs were non-specific for dehydration with a PPV of less than $0.5 .^{4-7}$

Based on these findings, it is reasonable to assume that, in a child with acute gastroenteritis, if all of the symptoms and signs listed are absent, then dehydration is unlikely. The presence of any of the features listed should alert the clinician to the possibility of dehydration while also being mindful that many of the features are non-specific and may indicate other illnesses.

One approach to rising awareness and to standardise care in this area has been the development of clinical decision tools. One such tool validated for use in children (aged 1 month-3 years) is the Clinical Dehydration Scale (CDS) ${ }^{8}$ summarised in table 2. Another useful resource is the National Institute for Health and Care Excellence (NICE) clinical guideline 84: 'Diarrhoea and vomiting 


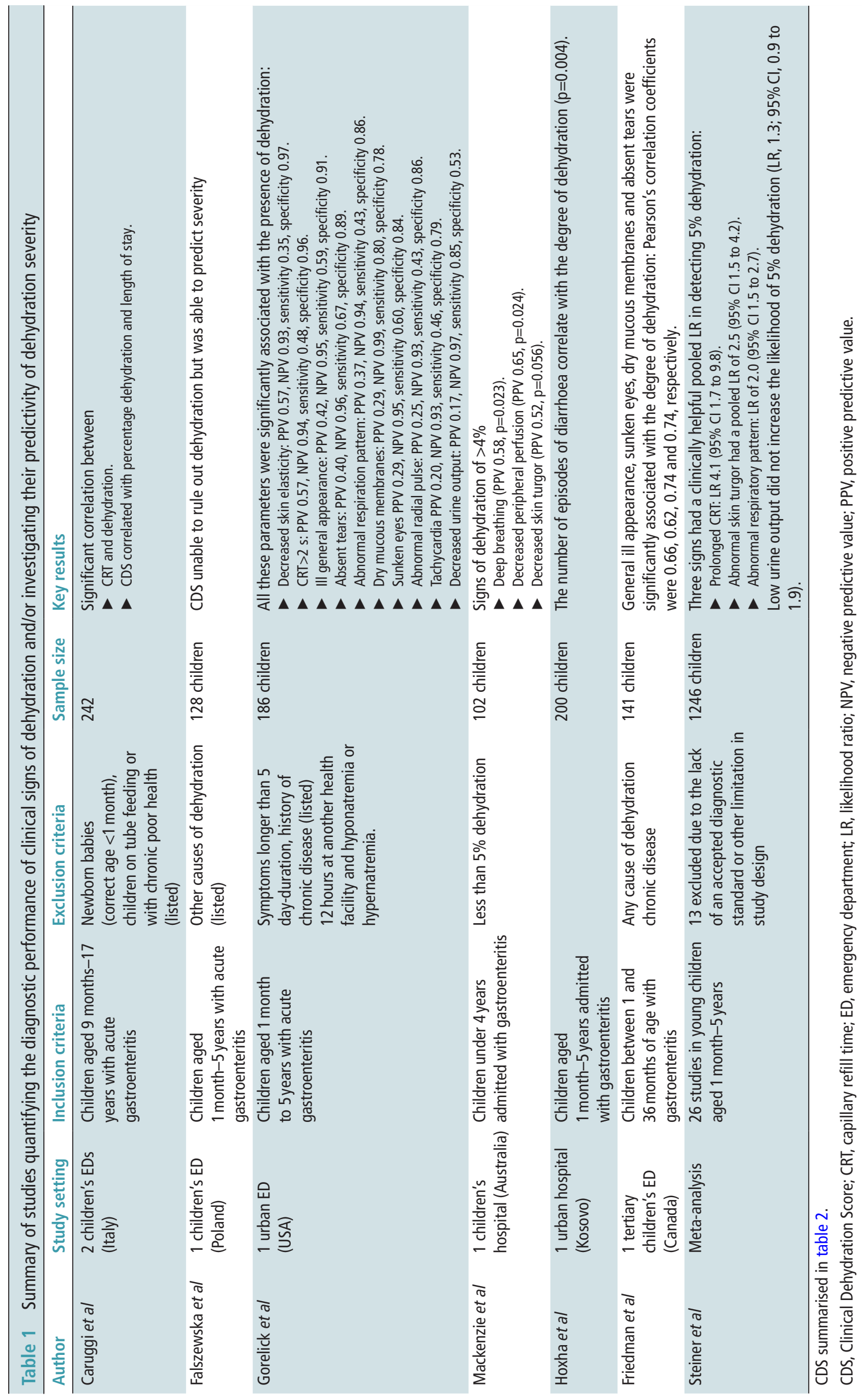




\begin{tabular}{|c|c|c|c|}
\hline Items & 0 & 1 & 2 \\
\hline $\begin{array}{l}\text { General } \\
\text { appearance }\end{array}$ & Normal & $\begin{array}{l}\text { Thirsty, restless, or } \\
\text { lethargic but irritable } \\
\text { when touched }\end{array}$ & $\begin{array}{l}\text { Disoriented, } \\
\text { hypotonic, cold } \\
\text { or sweaty skin, } \\
\text { unconscious }\end{array}$ \\
\hline Eyes & Normal & Slightly sunken & Very sunken \\
\hline $\begin{array}{l}\text { Mucous } \\
\text { membranes }\end{array}$ & Moist & 'Sticky' & Dry \\
\hline Tears & Tears & Decreased tears & Absent tears \\
\hline
\end{tabular}

A score of 0 represents no dehydration $(<3 \%)$; a score of $1-4$, some dehydration ( $\geq 3 \%-6 \%)$; and a score of $5-8$, moderate/severe dehydration $(\geq 6 \%)$.

caused by gastroenteritis in under $5 \mathrm{~s}$ : diagnosis and management'.

\section{WHICH SYMPTOMS AND SIGNS ARE BEST FOR PREDICTING THE SEVERITY OF DEHYDRATION?}

Predicting the severity of dehydration is challenging and requires the clinician to interpret and combine a mixture of symptoms and signs. When taking the history, it is important to ask about the number of episodes of diarrhoea and/or vomiting, as well as asking about intake, duration of illness and estimated urine output. Of the reported symptoms, it is the number of episodes of diarrhoea and/or vomiting that correlates best with severity. ${ }^{10}$

During the examination, it is important to make a global assessment of the child's health while also specifically examining for skin turgor, capillary refill time, dryness of mucous membranes, appearance of eyes (sunken or not) and the presence of tears. The individual predictive value of these signs has been discussed already (table 1), and the presence of any one feature should alert the clinician to possibility of dehydration. ${ }^{4-7}$ 10-12 The greater the number of features, the greater the likely degree of dehydration. ${ }^{6}$

The CDS provides a pragmatic approach to assessing severity (table 2) and can be used to aide decision making. ${ }^{48}$ Similarly, NICE CG84 provides guidance on assessing severity with features of dehydration listed, including five 'red flag' signs of 'reduced responsiveness, reduced skin turgor, tachycardia, tachypnoea and sunken eyes'.

\section{CAN LABORATORY INVESTIGATIONS BE USED TO ASSESS THE SEVERITY OF DEHYDRATION?}

NICE does not recommend routine blood testing in the assessment of dehydration in children. Blood testing is only recommended for children who require intravenous therapy, have signs of shock or where hyponatraemia/hypernatraemia is suspected. ${ }^{9}$ When testing is required, NICE only recommends measuring blood sugar, electrolytes, urea, creatinine and a blood gas. This approach is supported by the available evidence summarised in table $3 .^{71012-18}$
Measuring serum urea and creatinine levels is helpful when assessing severe dehydration only with very high serum urea values (greater than $16.7 \mathrm{mmol} / \mathrm{L}$ ) and creatinine values (greater than $80 \mu \mathrm{mol} / \mathrm{L}$ ) reliably predicting severe dehydration. ${ }^{10}{ }^{13}$ Unfortunately, urea and creatinine levels are unhelpful in mild and moderate dehydrations.

Of the tests advised by NICE, ${ }^{9}$ the blood gas (specifically bicarbonate levels) correlates the best with severity, as shown in table $4 .^{12} 131617$ As a general trend, the lower the venous bicarbonate levels, the greater the severity of dehydration. ${ }^{10}$

\section{WHAT ABOUT OTHER TESTS?}

There are a number of other tests that have been suggested as helpful in the assessment of dehydration in children. These include urinary testing (sodium and specific gravity) and blood tests (blood urea nitrogen ('BUN'), BUN to creatinine ratio and uric acid). ${ }^{12-14} 1718$

Urinary testing for specific gravity is of almost no value when assessing for dehydration and should not be routinely used. ${ }^{18}$ Urinary sodium levels may be helpful with a urine sodium of less than $90 \mathrm{mmol} / \mathrm{L}$ being shown to be highly sensitive and specific for dehydration. ${ }^{17} \mathrm{~A}$ urinary sodium may therefore be useful in children where the traditional clinical assessment of hydration may be difficult, for example, dehydration in conditions such as nephrotic syndrome.

Blood testing for BUN and BUN/creatinine levels may also be helpful in some. An elevated BUN greater than $45 \mathrm{mg} / \mathrm{dL}(16 \mathrm{mmol} / \mathrm{L})$ is indicative of at least moderate dehydration, ${ }^{12}$ whereas a BUN to creatinine ratio of less than 20 is indicative of an absence of dehydration. ${ }^{14}$

\section{EXPERIMENTAL TESTING}

The digitally measured capillary refill time (DCRT) is an innovative approach for predicting dehydration severity. The test requires use of specific software to analyse 'frame-by-frame' the video of one of the child's fingertips both before and after a light pressure is applied for $5 \mathrm{~s}$. Studies have demonstrated that a DCRT of $>0.4 \mathrm{~s}$ was $100 \%$ sensitive $(95 \%$ CI $75 \%$ to $100 \%)$ and had a specificity of $91 \%$ (95\% CI $82 \%$ to 97\%) for predicting the presence of at least moderate dehydration. ${ }^{19}$

Ultrasound (US) scanning has been proposed as a quick method to determine the severity of dehydration in children. Two different US measures (aorta to inferior vena cava (IVC) ratio and IVC inspiratory collapse) have been studied as methods of estimating dehydration in children. The aorta to IVC ratio demonstrated a sensitivity of $93 \%$ and specificity of $59 \%$ compared with $93 \%$ and $35 \%$ for IVC inspiratory collapse. ${ }^{20}$ The use of US remains experimental but could become of greater clinical relevance as point-of-care US becomes more widely available. ${ }^{20}$ 


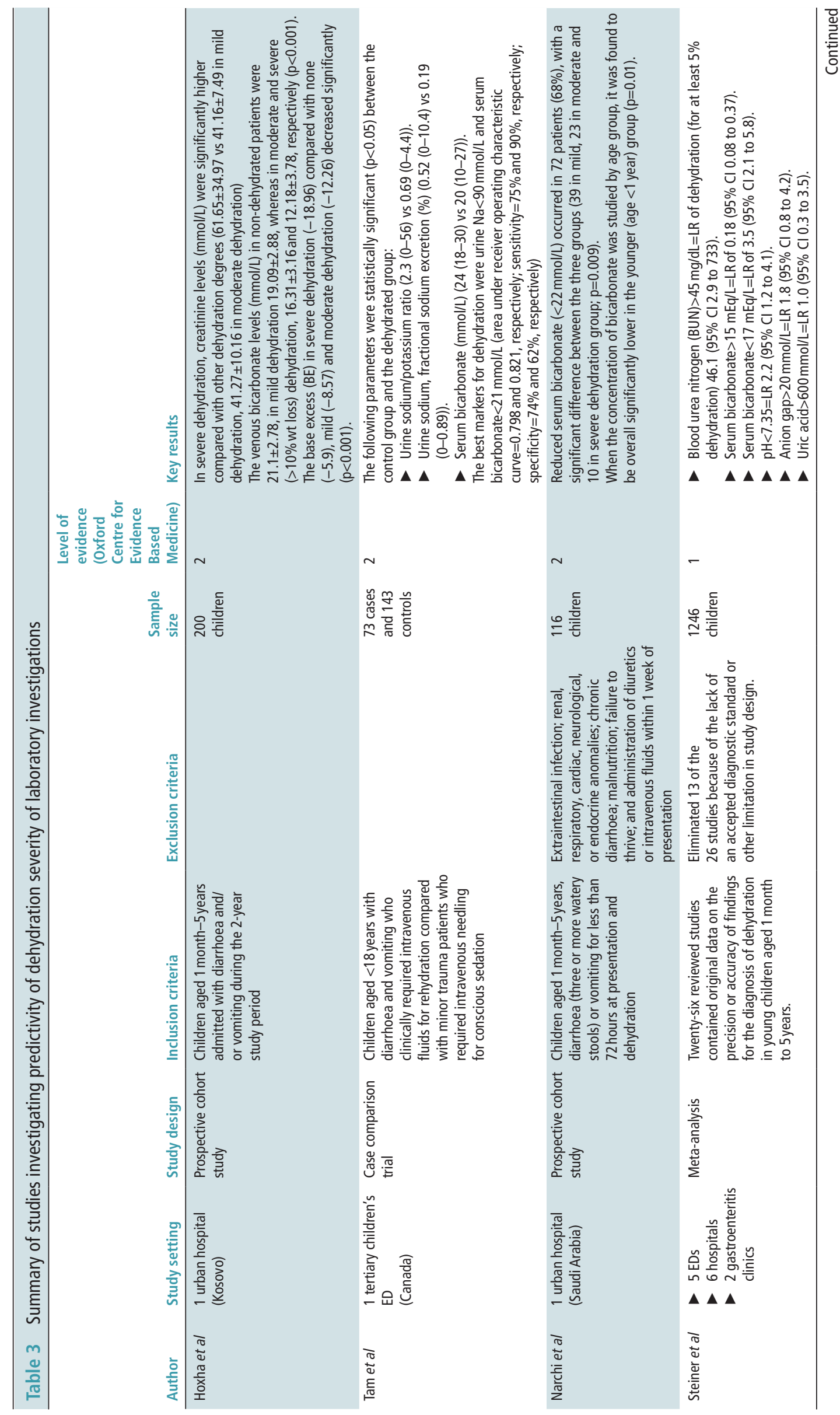




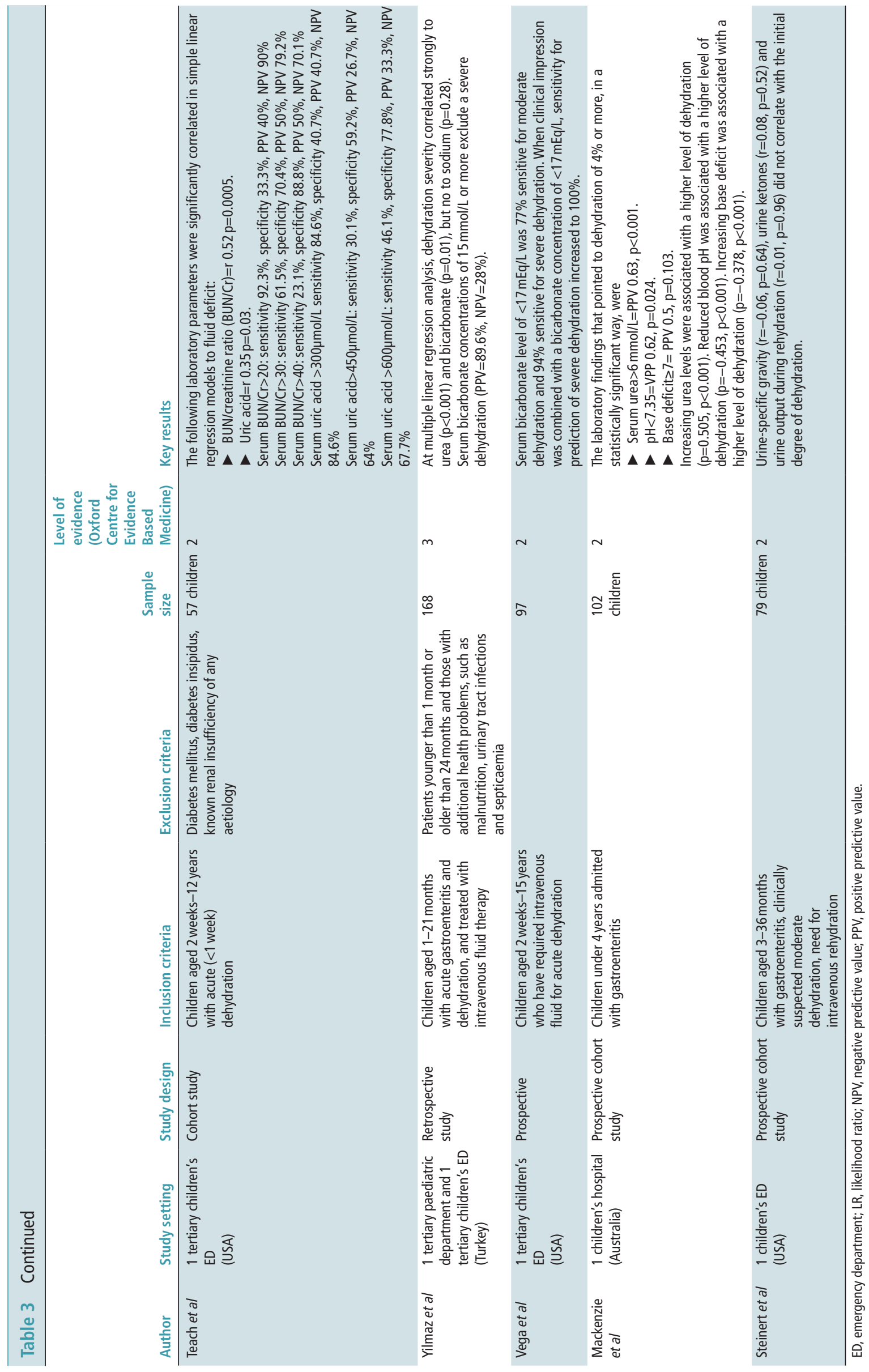


Table 4 Mean \pm SD of venous bicarbonate and base excess levels in relation to dehydration levels

\begin{tabular}{|c|c|c|c|c|c|}
\hline & $\begin{array}{l}\text { Non-dehydrated } \\
\text { patients }\end{array}$ & Mild dehydration & $\begin{array}{l}\text { Moderate } \\
\text { dehydration }\end{array}$ & $\begin{array}{l}\text { Severe } \\
\text { dehydration }\end{array}$ & $P$ value \\
\hline Venous bicarbonate levels ( $\mathrm{mmol} / \mathrm{L}$ ) & $21.1 \pm 2.78$ & $19.09 \pm 2.88$ & $16.31 \pm 3.16$ & $12.18 \pm 3.78$ & 0.001 \\
\hline Base excess & $-5.9 \pm 3.29$ & $-8.57 \pm 3.91$ & $-12.26 \pm 4.31$ & $-18.96 \pm 4.92$ & 0.001 \\
\hline
\end{tabular}

\section{Clinical bottom line}

- The assessment of dehydration in children is challenging and requires a detailed history and examination.

- Blood tests should not be performed routinely.

- The greater the number of symptoms and signs, the greater the likelihood of severe dehydration.

- The Clinical Dehydration Scale and National Institute for Health and Care Excellence CG84 are useful tools to help clinicians identify children with dehydration.

Contributors $A P, D C, S G, E M d G$ and PM equally contributed to the literature revision, manuscript draft and manuscript critical revision.

Funding The authors have not declared a specific grant for this research from any funding agency in the public, commercial or not-for-profit sectors.

Competing interests None declared.

Patient consent for publication Not required.

Provenance and peer review Commissioned; externally peer reviewed.

Data availability statement There are no data in this work

\section{ORCID iDs}

Daniela Capalbo http://orcid.org/0000-0002-3612-7383

Pierluigi Marzuillo http://orcid.org/0000-0003-4682-0170

\section{REFERENCES}

1 Powers KS. Dehydration: Isonatremic, Hyponatremic, and hypernatremic recognition and management. Pediatr Rev 2015;36:274-85.

2 Black RE, Morris SS, Bryce J. Where and why are 10 million children dying every year? Lancet 2003;361:2226-34.

3 World Health Organization. The treatment of diarrhoea: $a$ manual for physicians and other senior health workers. 4th edn. World Health Organization, 2005.

4 Falszewska A, Dziechciarz P, Szajewska H. Diagnostic accuracy of clinical dehydration scales in children. Eur J Pediatr 2017;176:1021-6.

5 Caruggi S, Rossi M, De Giacomo C, et al. Pediatric dehydration assessment at triage: prospective study on refilling time. Pediatr Gastroenterol Hepatol Nutr 2018;21:278-88.

6 Gorelick MH, Shaw KN, Murphy KO. Validity and reliability of clinical signs in the diagnosis of dehydration in children. Pediatrics 1997;99:E6.

7 Mackenzie A, Barnes G, Shann F. Clinical signs of dehydration in children. Lancet 1989;2:605-7.
8 Guarino A, Albano F, Ashkenazi S, et al. European Society for paediatric gastroenterology, hepatology, and Nutrition/ European Society for paediatric infectious diseases evidencebased guidelines for the management of acute gastroenteritis in children in Europe: Executive summary. J Pediatr Gastroenterol Nutr 2008;46:619-21.

9 National Collaborating Centre for Women's and Children's Health (UK). Diarrhoea and vomiting caused by gastroenteritis: diagnosis, assessment and management in children younger than 5 years. London: RCOG Press, 2009.

10 Hoxha TF, Azemi M, Avdiu M, et al. The usefulness of clinical and laboratory parameters for predicting severity of dehydration in children with acute gastroenteritis. Med Arch 2014;68:304-5.

11 Friedman JN, Goldman RD, Srivastava R, et al. Development of a clinical dehydration scale for use in children between 1 and 36 months of age. J Pediatr 2004;145:201-7.

12 Steiner MJ, DeWalt DA, Byerley JS. Is this child dehydrated? JAMA 2004;291:2746-54.

13 Yilmaz K, Karaböcüoglu M, Çitak A, et al. Evaluation of laboratory tests in dehydrated children with acute gastroenteritis. J Paediatr Child Health 2002;38:226-8.

14 Teach SJ, Yates EW, Feld LG. Laboratory predictors of fluid deficit in acutely dehydrated children. Clin Pediatr 1997;36:395-400.

15 Narchi H. Serum bicarbonate and dehydration severity in gastroenteritis. Arch Dis Child 1998;78:70-1.

16 Vega RM, Avner JR. A prospective study of the usefulness of clinical and laboratory parameters for predicting percentage of dehydration in children. Pediatr Emerg Care 1997;13:17982.

17 Tam RK, Wong H, Plint A, et al. Comparison of clinical and biochemical markers of dehydration with the clinical dehydration scale in children: a case comparison trial. BMC Pediatr 2014;14:149.

18 Steiner MJ, Nager AL, Wang VJ. Urine specific gravity and other urinary indices: inaccurate tests for dehydration. Pediatr Emerg Care 2007;23:298-303.

19 Shavit I, Brant R, Nijssen-Jordan C, et al. A novel imaging technique to measure capillary-refill time: improving diagnostic accuracy for dehydration in young children with gastroenteritis. Pediatrics 2006;118:2402-8.

20 Levine AC, Shah SP, Umulisa I, et al. Ultrasound assessment of severe dehydration in children with diarrhea and vomiting. Acad Emerg Med 2010;17:1035-41. 